\title{
Skeletal Muscle Metabolism Is a Major Determinant of Resting Energy Expenditure
}

Francesco Zurlo, Karen Larson, Clifton Bogardus, and Eric Ravussin

Clinical Diabetes and Nutrition Section, National Institute of Diabetes and Digestive and Kidney Diseases,

National Institutes of Health, Phoenix, Arizona 85016

\begin{abstract}
Energy expenditure varies among people, independent of body size and composition, and persons with a "low" metabolic rate seem to be at higher risk of gaining weight. To assess the importance of skeletal muscle metabolism as a determinant of metabolic rate, 24-h energy expenditure, basal metabolic rate (BMR), and sleeping metabolic rate (SMR) were measured by indirect calorimetry in 14 subjects $(7$ males, 7 females; $30 \pm 6$ yr [mean $\pm \mathrm{SD}$; $79.1 \pm 17.3 \mathrm{~kg} ; 22 \pm 7 \%$ body fat), and compared to forearm oxygen uptake. Values of energy expenditure were adjusted for individual differences in fat-free mass, fat mass, age, and sex. Adjusted BMR and SMR, expressed as deviations from predicted values, correlated with forearm resting oxygen uptake $\left(\mathrm{ml} \mathrm{O} \mathrm{O}_{2}\right.$ /liter forearm $)(r=0.72, P<0.005$ and $r$ $=0.53, P=0.05$, respectively). These findings suggest that differences in resting muscle metabolism account for part of the variance in metabolic rate among individuals and may play a role in the pathogenesis of obesity. (J. Clin. Invest. 1990. 86:1423-1427.) Key words: indirect calorimetry • forearm oxygen uptake $\bullet$ body composition
\end{abstract}

\section{Introduction}

Studies of metabolic rate in the basal state (BMR) ${ }^{1}$ or over $24 \mathrm{~h}$ in a respiratory chamber have shown significant variability among people. Differences in body weight accounted for only part of this variability (1-3); fat-free mass (FFM) was found to be the best determinant of BMR and 24-h energy expenditure (24EE) but accounted for only $60-80 \%$ of the variability observed between subjects. Some subjects have BMRs that are $>300 \mathrm{kcal} / \mathrm{d}$ above or below the prediction based on their FFM (4), and it has been recently demonstrated that both 24EE and BMR are familial traits independent of body size and body composition and may be genetically determined (3-5). Also, in prospective studies, it has been shown that a reduced rate of energy expenditure is a risk factor for body weight gain $(3,6)$. It is unclear, however, what causes the interindividual variability in energy expenditure and what tissues or organs may account for this variability.

Address correspondence and reprint requests to Dr. Eric Ravussin, National Institutes of Health, 4212 N. 16th St., Rm. 541, Phoenix, AZ 85016.

Received for publication 21 March 1990 and in revised form 8 June 1990.

1. Abbreviations used in this paper: BMR, metabolic rate in the basal state; 24EE, 24-hour energy expenditure; FFM, fat-free mass; SMR, sleeping metabolic rate.

The Journal of Clinical Investigation, Inc.

Volume 86, November 1990, 1423-1427
The metabolic rate in brain and kidney is constantly sustained and varies very little during the course of the day, whereas skeletal muscle metabolism changes dramatically from resting to maximal physical activity, during which muscle $\mathrm{O}_{2}$ consumption can account for up to $90 \%$ of the wholebody oxygen uptake. Because of its relatively low resting energy metabolism $(7,8)$, skeletal muscle has often been neglected when trying to explain interindividual differences in metabolic rate. However, because skeletal muscle comprises $\sim 40 \%$ of body weight in nonobese subjects (9), the tissue can account for $20-30 \%$ of the total resting oxygen uptake $(9,10)$. Skeletal muscle metabolism, therefore, might represent an important variable component and a determinant of whole-body resting metabolic rate.

The present study was conducted to explore the relationship between whole-body energy expenditure (over $24 \mathrm{~h}$, in the basal state, or when sleeping), and skeletal muscle metabolism as assessed by forearm resting oxygen uptake. We hypothesized that part of the variability between subjects in wholebody metabolic rate might be related to differences in skeletal muscle metabolism.

\section{Methods}

Subjects. 17 Caucasians were admitted to the clinical research ward of the Clinical Diabetes and Nutrition Section of the National Institutes of Health in Phoenix, AZ. Upon admission, all subjects were determined to be in good health by means of medical history, physical examination, electrocardiogram, blood screening, and urine tests. Subjects were not diabetic according to National Diabetes Data Group criteria (11). None was taking any medication or had clinical evidence of illness apart from obesity. Subjects were fed a weight-maintenance diet (50\% carbohydrate, $30 \%$ fat, and $20 \%$ protein) (12). The body density of each subject was determined by underwater weighing (13) with simultaneous measurement of residual lung volume, and percent body fat was calculated according to the Siri equation (14). Although 17 subjects were admitted for the study, forearm oxygen uptake measurements in three patients were unsuccessful due to technical problems with the catheterization procedure in the forearm. Therefore, results are presented for only 14 subjects. The protocol was approved by the NIDDK Clinical Research Subpanel, and written, informed consent was obtained from each subject. Subject characteristics are listed in Table I.

Energy expenditure measurements. After at least two full days on the metabolic ward, the subjects spent $24 \mathrm{~h}$ in a respiratory chamber where energy expenditure and spontaneous physical activity were measured as previously described (15). No vigorous exercise was allowed in the chamber. Measurements in the respiratory chamber were performed continuously for $23 \mathrm{~h}$ from 0800 to $0700 \mathrm{~h}$ and extrapolated to 24EE. Sleeping metabolic rate (SMR) was defined as the average energy expenditure of all 15 -min periods between 2330 and 0500 , during which the duration of spontaneous physical activity did not exceed $1.5 \%$ of the time. At 0700 the following morning, $11 \mathrm{~h}$ after the evening snack, the BMR was measured with a transparent ventilated hood. After $\sim 10 \mathrm{~min}$ of adaptation to the hood, the measurement 
Table I. Physical Characteristics of the Subjects

\begin{tabular}{lcrrrrrr}
\hline $\begin{array}{c}\text { Subject } \\
\text { No. }\end{array}$ & Sex & Age & Height & Weight & BMI & Body fat & $\begin{array}{c}\text { Waist/thigh } \\
\text { circumference } \\
\text { ratio }\end{array}$ \\
\hline & & $y r$ & $c m$ & $k g$ & $k g / m^{2}$ & $\%$ & \\
1 & M & 35 & 170.0 & 62.9 & 21.9 & 20 & 1.56 \\
2 & M & 29 & 176.0 & 68.3 & 22.1 & 9 & 1.38 \\
3 & M & 38 & 172.0 & 74.7 & 25.1 & 23 & 1.63 \\
4 & M & 28 & 178.0 & 85.8 & 26.6 & 17 & 1.59 \\
5 & M & 22 & 188.5 & 78.9 & 22.1 & 13 & 1.28 \\
6 & M & 33 & 181.7 & 108.3 & 33.1 & 28 & 1.58 \\
7 & M & 41 & 179.0 & 109.2 & 34.1 & 26 & 1.34 \\
8 & F & 25 & 178.2 & 68.1 & 21.2 & 16 & 1.47 \\
9 & F & 27 & 165.0 & 72.2 & 26.6 & 28 & 1.51 \\
10 & F & 29 & 162.5 & 56.2 & 21.7 & 20 & 1.41 \\
11 & F & 23 & 170.5 & 63.1 & 21.6 & 21 & 1.37 \\
12 & F & 33 & 176.2 & 68.4 & 22.2 & 23 & 1.32 \\
13 & F & 26 & 168.5 & 90.4 & 31.8 & 29 & 1.51 \\
14 & F & 35 & 165.0 & 101.3 & 36.8 & 37 & 1.54 \\
Mean & & 30 & 173.7 & 79.1 & 26.2 & 22 & 1.46 \\
SD & & 6 & 7.3 & 17.3 & 5.5 & 7 & 0.11 \\
& & & & & & & \\
\hline & & & & & & & \\
\hline
\end{tabular}

continued for another $30 \mathrm{~min}$ and BMR was calculated as the mean of the five 3-min periods with the lowest energy expenditure. Values of 24EE, BMR, and SMR were expressed on a 24-h basis. Adjusted values of energy expenditure (24EE, BMR, and SMR) were calculated from data collected on 138 healthy Caucasians ( 86 males, 52 females; $28 \pm 7$ $\mathrm{yr} ; 92.4 \pm 32.3 \mathrm{~kg} \mathrm{wt} ; 26 \pm 12 \%$ body fat) with the general linear model procedure with four covariates: FFM, fat mass (FM), age, and sex. In the present study, the residuals between the measured and predicted values were used as an index of the adjusted energy expenditure.

Forearm oxygen uptake. Forearm oxygen uptake was measured in each subject three times at 40 -min intervals. At 0730 , after an overnight fast, a 20-gauge arterial catheter (Arrow International, Inc., Reading, PA) was placed under local anesthesia in the radial artery of the nondominant arm and kept open by arterial pressure saline microinfusion (Transpac II, Abbott Laboratories, N. Chicago, IL). An 18or 20-gauge catheter was then placed, retrogradely, in a deep antecubital vein of the dominant forearm and connected to a saline solution for continuous microinfusion. The subject's forearm was supported and kept immobile by pillows. After $\mathbf{4 0} \mathrm{min}$ of complete rest, direct blood flow measurement across the forearm was obtained with a capacitance plethysmograph (model 2560, UFI, Morro Bay, CA), the cuff of which was placed 5-6 $\mathrm{cm}$ below the elbow. $1 \mathrm{~min}$ before the blood flow determination, a pneumatic pediatric cuff placed around the wrist was inflated to $\sim 150 \mathrm{~mm} \mathrm{Hg}$ higher than systolic blood pressure, excluding the vascular region of the hand. A second cuff placed proximal to the plethysmograph cuff was then inflated to a pressure of $50 \mathrm{~mm} \mathrm{Hg}$ to allow blood flow measurement according to the venous occlusion method, as described by Bernstein (16). Shortly after venous occlusion, the increase in forearm volume monitored by the plethysmograph was prevented for $\sim 30-60 \mathrm{~s}$ by drawing continuously $20-40 \mathrm{ml}$ of blood from the deep vein in a $60-\mathrm{ml}$ plastic syringe so as to reach a steady state between forearm inflow and forearm outflow. At the end of this flow measurement, before reinfusing the venous blood, venous and arterial blood samples were simultaneously collected and immediately analyzed for total blood oxygen content using a cooximeter (IL482 Co-Oximeter, Instrumentation Laboratory, Lexington, MA). At the end of the test, the forearm volume between the two pneumatic cuffs was measured by water displacement. The hand was first immersed up to the wrist mark and the water was discarded, whereas the water displaced during the second immersion up to the "elbow mark" was volumetrically measured; forearm oxygen uptake (milliliters per minute per 1 forearm volume) was calculated as: forearm blood flow (milliliters per minute) $\cdot\left(\right.$ arterial $\mathrm{O}_{2}$ content - venous $\mathrm{O}_{2}$ content [milliliters $\mathrm{O}_{2}$ per milliliter])/volume forearm (l). The composition (muscle mass versus nonmuscle mass) of the forearm was assessed with computerized tomography at $1 / 4,1 / 2$, and $3 / 4$ of the distance between the elbow and the ulnar styloid process (17). A computerized measurement of muscle area including other soft tissues was performed by the CT scanner (GEE CTT 9800 46/236955 G1) using a density mask (from +15 to +150 Hounsfield units) to highlight muscle tissue in each cross-section. Similarly, total cross-sectional area was also measured using a density mask (from -250 to $+3,000$ Hounsfield units). We considered that the average surface occupied by muscle in the three cross-sectional slices was representative of the total forearm. Forearm oxygen uptake was also expressed per unit of muscle and nonmuscle volumes.

Calculations and statistical analyses. Data are expressed as mean \pm standard deviation. Statistical analyses were performed with the procedures of the Statistical Analysis System (SAS, Inc., Cary, NC) (18). Correlations are Pearson product-moment correlations. Regression coefficients were determined with the general linear model procedure.

\section{Results}

Energy expenditure. Individual values of 24EE, BMR, and SMR are shown in Table II. The residual energy expenditure (difference between the measured energy expenditure and the energy expenditure predicted on the basis of fat-free mass, fat mass, age, and sex) of the 14 subjects studied varied from -347 to $+565 \mathrm{kcal} / \mathrm{d}$ for $24 \mathrm{EE}$, from -305 to $+416 \mathrm{kcal} / \mathrm{d}$ for BMR (Figs. 1 and 2), and -154 to $+235 \mathrm{kcal} / \mathrm{d}$ for SMR.

Forearm oxygen uptake. Individual values are shown in Table III. The forearm arterial oxygen content averaged $17.5 \pm 1.4 \mathrm{ml} / \mathrm{dl}$ blood, with $95 \%$ saturation $\mathrm{O}_{2}$ (range, 92-97), and the forearm venous oxygen content was $11.9 \pm 1.6 \mathrm{ml} / \mathrm{dl}$ blood, with $64 \%$ (range, 55-73) $\mathrm{O}_{2}$ saturation. The mean within-subject coefficient of variation of the three measurements in each subject was 1.2 and $6.2 \%$ for arterial and venous oxygen content, respectively. The forearm blood flow averaged $29 \pm 10 \mathrm{ml} / \mathrm{min}$ (range, 13-47) with a mean within-subject coefficient of variation of $10.1 \%$. The mean oxygen uptake per volume of forearm tissue was $1.29 \pm 0.35$ [ml/(1 forearm $\times$ min)] (range, $0.68-1.81$ ) with a mean within-subject coefficient of variation of $13.5 \%$.

Forearm oxygen uptake (milliliters per minute) correlated with forearm total volume and forearm muscle volume ( $r$ $=0.76, P<0.002$ and $r=0.71, P<0.005$, respectively), but not with the forearm nonmuscle volume $(r=0.35, P=0.22)$. However, by multiple linear regression, forearm oxygen uptake was related to forearm muscle and nonmuscle volumes as independent covariates (for model: $r^{2}=0.61, P=0.005$ ).

Energy expenditure versus muscle oxygen uptake. The ad-justed BMR (expressed as measured - predicted BMR) correlated with oxygen uptake both per volume of forearm (Fig. 1, $r$ $=0.72, P<0.005)$ and adjusted for forearm muscle and nonmuscle volumes (Fig. $2, r=0.61, P<0.03$ ). A similar relationship was found between the adjusted SMR and forearm oxygen uptake expressed per volume of forearm or adjusted for muscle and nonmuscle volume $(r=0.53, P=0.05$ and $r$ $=0.57, P<0.05$, respectively). No significant relationship was found, however, between the adjusted 24EE and the forearm oxygen uptake $(r=0.41, P=0.15$ and $r=0.25, P=0.38$, respectively). 
Table II. Subjects' 24EE, BMR, and SMR

\begin{tabular}{|c|c|c|c|c|c|c|}
\hline \multirow[b]{2}{*}{$\begin{array}{l}\text { Subject } \\
\text { No. }\end{array}$} & \multicolumn{2}{|c|}{$24 \mathrm{EE}$} & \multicolumn{2}{|c|}{ Basal metabolic rate } & \multicolumn{2}{|c|}{ Sleeping metabolic rate } \\
\hline & Measured & $\begin{array}{l}\text { Measured } \\
\text { - predicted* }\end{array}$ & Measured & $\begin{array}{l}\text { Measured } \\
\text { - predicted* }\end{array}$ & Measured & $\begin{array}{c}\text { Measured } \\
\text { - predicted }\end{array}$ \\
\hline & $\mathrm{kcal} / \mathrm{d}$ & $\mathrm{kcal} / \mathrm{d}$ & $k c a l / d$ & $\mathrm{kcal} / \mathrm{d}$ & $\mathrm{kcal} / \mathrm{d}$ & $\mathrm{kcal} / \mathrm{d}$ \\
\hline 1 & 1964 & 40 & 1515 & 19 & 1485 & 130 \\
\hline 2 & 2434 & 351 & 1810 & 101 & 1750 & 235 \\
\hline 3 & 2169 & 83 & 2022 & 416 & 1545 & 65 \\
\hline 4 & 1978 & -347 & 1634 & -259 & 1542 & -154 \\
\hline 5 & 2423 & 175 & 1977 & 107 & 1644 & 2 \\
\hline 6 & 2455 & -139 & 2158 & 120 & 1799 & -81 \\
\hline 7 & 3170 & 565 & 2052 & 29 & 1820 & -75 \\
\hline 8 & 1984 & 135 & 1470 & -79 & 1365 & -51 \\
\hline 9 & 1635 & -212 & 1422 & -70 & 1339 & -45 \\
\hline 10 & 1534 & -97 & 1023 & -305 & 1104 & -122 \\
\hline 11 & 1720 & -28 & 1266 & -186 & 1300 & -20 \\
\hline 12 & 1817 & 13 & 1385 & -63 & 1426 & 63 \\
\hline 13 & 2329 & 203 & 1770 & 44 & 1685 & 77 \\
\hline 14 & 2166 & -46 & 1725 & 21 & 1624 & -22 \\
\hline Mean & 2127 & 50 & 1659 & -8 & 1531 & 0 \\
\hline SD & 425 & 233 & 331 & 180 & 208 & 105 \\
\hline
\end{tabular}

* Predicted values of 24EE, BMR, and SMR were calculated by multiple linear regressions according to FFM, fat mass, age, and sex of each individual using equations developed in 138 nondiabetic Caucasians.

\section{Discussion}

The present study shows that in 14 healthy young adults, BMR and SMR, adjusted for individual differences in FFM, fat mass, age, and sex, are significantly related to forearm resting oxygen uptake. These results suggest that resting muscle tissue metabolism might explain part of the variability in resting metabolic rate observed in people.

Table III. Forearm Volumes, Arterial and Venous Blood Oxygen Contents, Forearm Blood Flows, and Oxygen Uptakes in 14 Volunteers

\begin{tabular}{|c|c|c|c|c|c|c|}
\hline \multirow{2}{*}{$\begin{array}{c}\text { Subject } \\
\text { No. }\end{array}$} & \multicolumn{2}{|c|}{ Forearm volume } & \multicolumn{2}{|c|}{ Oxygen content $t^{*}$} & \multirow[b]{2}{*}{ Forearm flow ${ }^{*}$} & \multirow[b]{2}{*}{ Forearm $\mathrm{O}_{2}$ uptake* } \\
\hline & Total vol & Muscle vol & Arterial blood & Venous blood & & \\
\hline & $m l$ & $m l$ & $\mathrm{ml} / \mathrm{dl}$ & $\mathrm{ml} / \mathrm{dl}$ & $\mathrm{ml} / \mathrm{min}$ & $\mathrm{ml} /($ liter forearm $\times$ min $)$ \\
\hline 1 & 1070 & 742 & $17.5 \pm 0.1$ & $12.1 \pm 0.6$ & $29 \pm 3.2$ & $1.47 \pm 0.13$ \\
\hline 2 & 1138 & 933 & $19.6 \pm 0.2$ & $14.4 \pm 1.0$ & $34 \pm 4.8$ & $1.52 \pm 0.15$ \\
\hline 3 & 1107 & 742 & $17.1 \pm 0.2$ & $10.7 \pm 0.4$ & $32 \pm 3.5$ & $1.81 \pm 0.25$ \\
\hline 4 & 1296 & 842 & $18.8 \pm 0.2$ & $14.0 \pm 0.4$ & $34 \pm 5.8$ & $1.23 \pm 0.18$ \\
\hline 5 & 1390 & 1017 & $18.4 \pm 0.1$ & $11.7 \pm 0.6$ & $27 \pm 0.5$ & $1.29 \pm 0.12$ \\
\hline 6 & 1640 & 1000 & $19.4 \pm 0.3$ & $14.8 \pm 0.6$ & $47 \pm 4.2$ & $1.31 \pm 0.13$ \\
\hline 7 & 1600 & 944 & $19.5 \pm 0.3$ & $11.0 \pm 1.0$ & $27 \pm 2.2$ & $1.41 \pm 0.17$ \\
\hline 8 & 1080 & 676 & $15.9 \pm 0.6$ & $9.6 \pm 1.0$ & $16 \pm 1.3$ & $0.94 \pm 0.01$ \\
\hline 9 & 940 & 461 & $15.5 \pm 0.1$ & $11.9 \pm 2.0$ & $20 \pm 5.2$ & $0.68 \pm 0.27$ \\
\hline 10 & 1117 & 656 & $16.5 \pm 0.3$ & $9.8 \pm 0.1$ & $13 \pm 0.9$ & $0.78 \pm 0.08$ \\
\hline 11 & 1074 & 615 & $16.2 \pm 0.1$ & $11.8 \pm 0.5$ & $23 \pm 0.7$ & $0.87 \pm 0.07$ \\
\hline 12 & 1140 & 630 & $16.9 \pm 0.3$ & $11.3 \pm 1.0$ & $27 \pm 3.5$ & $1.31 \pm 0.39$ \\
\hline 13 & 1297 & 765 & $17.1 \pm 0.3$ & $10.9 \pm 0.8$ & $37 \pm 1.9$ & $1.74 \pm 0.21$ \\
\hline 14 & 1400 & 758 & $16.9 \pm 0.2$ & $11.9 \pm 0.5$ & $46 \pm 2.8$ & $1.63 \pm 0.16$ \\
\hline Mean & 1235 & 770 & 17.5 & 11.9 & 29 & 1.29 \\
\hline SD & 209 & 161 & 1.4 & 1.6 & 10 & 0.35 \\
\hline
\end{tabular}

* Arterial and venous $\mathrm{O}_{2}$ content were obtained in total blood samples measuring total hemoglobin and hemoglobin percent oxygen saturation. ${ }^{\ddagger}$ Mean \pm SD of three measurements done in each subject. 


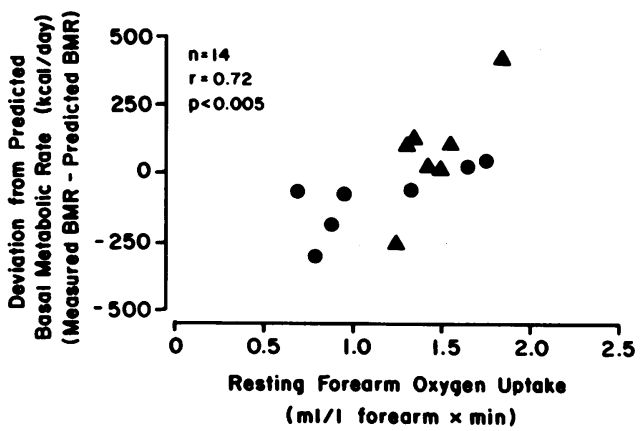

Figure 1. Relationship between the deviation of the measured basal metabolic rate (BMR) (kcal/d) from the predicted BMR and forearm oxygen uptake expressed per liter of forearm tissue ( $\mathrm{ml} /[$ liters $X$ min]). Correlation coefficients were 0.80 and 0.75 for males $(\triangle)$ and females $(\bullet)$, respectively. The predicted BMR was calculated accounting for subjects' FFM, fat mass (FM), age, and sex based on measurements in 138 nondiabetic Caucasians (BMR [kcal/d] $=940$ $+16.6 \times$ FFM $[\mathrm{kg}]+3.9 \times$ FM $[\mathrm{kg}]-6.3 \times$ age $[\mathrm{y}]-112 \times$ sex [male $=1$, female $=2$ ]; $r^{2}=0.66, P<0.0001$ )

The role of skeletal muscle in whole-body BMR and SMR has often been neglected on the basis of its low resting metabolic rate, with oxygen uptake per gram of resting tissue $\sim 2.5 \%$ of that consumed by a gram of kidney or heart tissue (19). However, skeletal muscle accounts for $40-50 \%$ of body weight in normal-weight individuals (9) and is therefore, quantitatively, the most important tissue mass of the body. If muscle alone accounted for all of the forearm metabolism, oxygen consumption would be $2.2 \mathrm{ml} / \mathrm{min}$ per liter of muscle $(1.3$ $\mathrm{ml} / \mathrm{min}$ divided by 0.60 because in our study muscle represented $\sim 60 \%$ of total forearm volume). Assuming $30 \mathrm{~kg}$ skeletal muscle in a 70-kg man, muscle oxygen uptake would represent $66 \mathrm{ml} / \mathrm{min}$ of oxygen uptake, i.e., $30 \%$ of whole-body

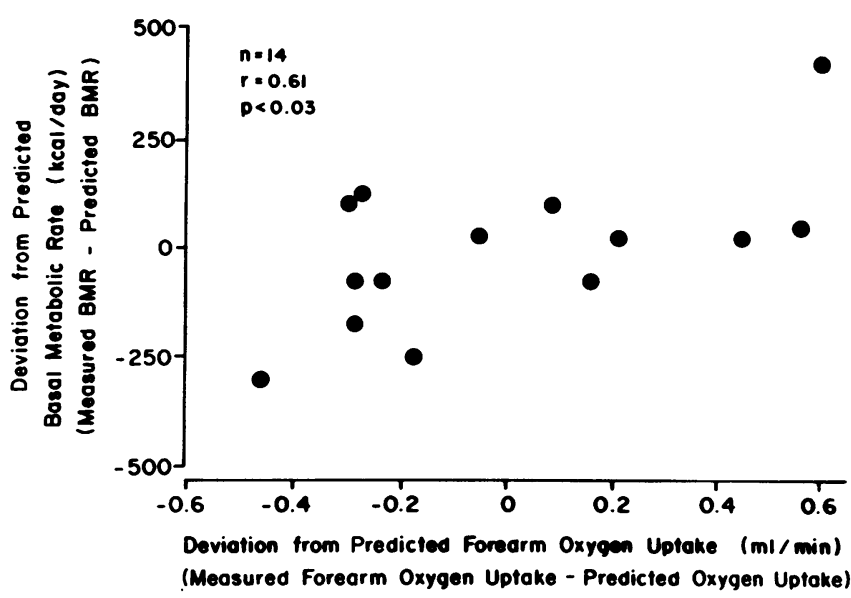

Figure 2. Relationship between the deviation of the measured BMR $(\mathrm{kcal} / \mathrm{d})$ from the predicted BMR and the deviation of the measured forearm oxygen uptake ( $\mathrm{ml} / \mathrm{min}$ ) from the predicted forearm oxygen uptake calculated accounting for individual differences in forearm muscle and nonmuscle volumes [forearm oxygen uptake $(\mathrm{ml} / \mathrm{min})$ $=-0.93+0.0024 \times$ muscle volume (liters) $+0.0014 \times$ nonmuscle volume (liters), $n=14, r^{2}=0.61, P=0.005$ ). Forearm muscle and nonmuscle volumes were determined by computerized tomography Correlation coefficients were 0.61 and 0.78 for males and females, respectively. metabolism. However, considering that the other forearm tissues also utilize oxygen for their metabolism, muscle oxygen consumption might represent at least $1.6 \mathrm{ml} / \mathrm{min}$ per liter and account for at least $\sim 20 \%$ of the whole-body oxygen uptake. Also, the relationships between the variability of BMR and the variability of forearm oxygen uptake indicate that $40-50 \%$ of the variability in metabolic rate (adjusted for differences in FFM, fat mass, age, and sex) can be ascribed to the variability in forearm metabolism and most likely to the variability in resting skeletal muscle metabolic rate.

Resting muscle metabolism was assessed by three forearm oxygen uptake measurements; the overall variability of this measurement was $13.5 \%$ (mean C.V. within subjects). Using this particular technique, errors may arise from two sources: (a) blood oxygen content determinations; $(b)$ blood flow determination. The error involved with the measurement of blood oxygen content was very small. In fact, the arterial oxygen content was highly reproducible within subjects, with a mean coefficient of variation $<1.5 \%$. Therefore the higher variability observed in venous oxygen content $(6 \%)$ can be safely ascribed to physiological differences. The forearm blood flow determination had a mean coefficient of variation of $\sim 10 \%$. Only two subjects (No. 9 and No. 12) had coefficients of variation between measurements exceeding $20 \%$. However, the correlations between forearm oxygen uptake and other variables did not change regardless of whether or not these two subjects were included in the analysis.

In conclusion, resting muscle metabolism is positively associated with the differences in resting energy expenditure observed among people and represents a major determinant of the interindividual variation in energy expenditure. Obesity is a multifactorial syndrome in which a deficit in resting metabolic rate has been shown to play a significant role $(3,6)$. Consequently, people with lower resting muscle metabolism might in fact be at higher risk for sustaining positive energy balance and therefore gaining weight. Several factors might influence the variation in muscle energy expenditure, such as thyroid hormone (perhaps even within "normal" ranges), muscle fiber types, muscle tone, sympathetic innervation, and/or catecholamines levels. Recently, in support of the present finding, Wade et al. presented data emphasizing the relationship between muscle fiber types and body composition and suggested that muscle fiber type might be an etiological factor for obesity (20). Also, Astrup et al. reported that skeletal muscle was the site of part of the facultative thermogenesis in response to carbohydrate feeding via $\beta_{2}$-adrenergic receptor stimulation by epinephrine (21). Emorine et al. also proposed in their report of the "molecular characterization of the human $\beta_{3}$-adrenergic receptor" that muscle oxygen uptake can be mediated by the norepinephrine released from the sympathetic innervation via $\beta_{3}$-receptors (22). Taken together, these results suggest that skeletal muscle is a potential site for the variability of metabolic rate observed between people.

\section{Acknowledgments}

We are indebted to Ms. Carol Lamkin and the nursing staff of the research unit, Vicky Boyce and the dietary staff, Susan Elson for help in preparing the manuscript, Dr. William Johnson for his help with arterial catheterization techniques, Dr. Stephen Lillioja and Mr. Tom Anderson for their help in conducting the study, Mrs. Laura Castillo and the staff of St. Joseph's Hospital for CT scan procedures, Dr. 
David M. Mott and the laboratory staff for their technical assistance, and all of the volunteers who have made this study possible.

This study was supported in part by a grant from the Diabetes Research and Education Foundation.

\section{References}

1. Widdowson, E. M., O. G. Edholm, and R. A. McCance. 1954. The food intake and energy expenditure of cadets in training. $B r . J$. Nutr. 8:147-155.

2. Boothby, W. M., and I. Sandiford. 1922. Summary of the basal metabolism data on 8,614 subjects with special reference to the norma standards for the estimation of the basal metabolic rate. J. Biol. Chem. 54:783-803.

3. Ravussin, E., S. Lillioja, W. C. Knowler, L. Christin, D. Freymond, W. G. H. Abbott, V. Boyce, B. V. Howard, and C. Bogardus. 1988. Reduced rate of energy expenditure as a risk factor for bodyweight gain. N. Engl. J. Med. 318:467-472.

4. Bogardus, C., S. Lillioja, E. Ravussin, W. Abbott, J. K. Zawadzki, A. Young, W. C. Knowler, R. Jacobowitz, and P. P. Moll. 1986. Familial dependence of the resting metabolic rate. $N$. Engl. J. Med. 315:96-100.

5. Bouchard, C., A. Tremblay, A. Nadeau, J. P. Despres, G. Theriault, M. R. Boulay, G. Lortie, C. Leblanc, and G. Fournier. 1989. Genetic effect in resting and exercise metabolic rates. Metabolism. 38:364-370.

6. Roberts, S. B., J. Savage, W. A. Coward, B. Chew, and A. Lucas. 1988. Energy expenditure and intake in infants born to lean and overweight mothers. N. Engl. J. Med. 318:461-466.

7. Stainsby, W. N., and C. Lambert. 1979. Determinants of oxygen uptake in skeletal muscle. Exercise Sport Sci. Rev. 7:125-151.

8. Astrup, A., L. Simonsen, J. Bulow, and N. J. Christensen. 1988. Measurement of forearm oxygen consumption: role of heating the contralateral hand. Am. J. Physiol. 255:E572-E578.

9. Owen, O. E., G. A. Reichard, Jr., G. Boden, M. S. Patel, and V. E. Trapp. 1978. Interrelationships among key tissues in the utilization of metabolic substrate. Adv. Mod. Nutr. 2:517-550.

10. Wade, O. L., and J. M. Bishop. 1962. Cardiac Output and Regional Blood Flow. Blackwell Scientific Publications, Oxford, UK.
11. National Diabetes Data Group. 1979. Classification and diagnosis of diabetes mellitus and other categories of glucose intolerance. Diabetes. 38:1039-1057.

12. Abbott, W. G. H., B. V. Howard, L. Christin, D. Freymond, S. Lillioja, V. L. Boyce, T. E. Anderson, C. Bogardus, and E. Ravussin. 1988. Short-term energy balance: relationship with protein, carbohydrate, and fat balances. Am. J. Physiol. 255:E332-E337.

13. Goldman, R. F., and E. R. Buskirk. 1961. Body volume measurement by underwater weighing: description of a method. In Techniques for Measuring Body Composition. J. Brozek and A. Henschel, editors. National Research Council, National Academy of Sciences, Washington, DC. 78-106.

14. Siri, W. E. 1956. The gross composition of the body. Adv. Biol. Med. Phys. IV. Academic Press, Inc., New York. 239-280.

15. Ravussin, E., S. Lillioja, T. E. Anderson, L. Christin, and C. Bogardus. 1986. Determinants of 24-hour energy expenditure in man: methods and results using a respiratory chamber. J. Clin. Invest. 78:1568-1578.

16. Bernstein, E. F. 1982. Noninvasive diagnostic techniques in vascular disease. In Volume Plethysmography in Vascular Disease: An Overview. 2nd ed. D. S. Sumner, editor. C. V. Mosby Co., St. Louis, MO.

17. Maughan, R. J., J. S. Watson, and J. Weir. 1984. The relative proportions of fat, muscle and bone in the normal human forearm as determined by computed tomography. Clin. Sci. 66:683-689.

18. Statistical Analysis System Institute, Inc. 1985. SAS User's Guide: Statistics. Version 5 ed. SAS Institute, Cary, NC.

19. Rorer, H. C. 1973. Physiological Basis of Medical Practice, Section 3, 9th ed. J. R. Brobeck, editor. Williams \& Wilkins Co., Baltimore, MD. 124 pp.

20. Wade, A. J., M. M. Marbut, and J. M. Round. 1990. Muscle fiber type and aetiology of obesity. Lancet. 335:805-808.

21. Astrup, A., L. Simonsen, J. Bulow, J. Madsen, and N. J. Christensen. 1989. Epinephrine mediates facultative carbohydrate-induced thermogenesis in human skeletal muscle. Am. J. Physiol. 257:E340E345.

22. Emorine, L. J., S. Marullo, M.-M. Briend-Sutren, G. Patey, K. Tate, C. Delavier-Klutchko, and A. D. Strosberg. 1989. Molecular characterization of the human $\beta_{3}$-adrenergic receptor. Science (Wash. DC). 245:1118-1121. 